\title{
Using the World Apheresis Association Registry Helps to Improve the Treatment Quality of Therapeutic Apheresis
}

\author{
Bernd Stegmayr $^{\mathrm{a}}$ Elizabeth Newman ${ }^{\mathrm{b}}$ Volker Witt $^{\mathrm{c}}$ Kurt Derfler $^{\mathrm{d}} \quad$ Gerda Leitner $^{\mathrm{e}}$ \\ Sunny Eloot ${ }^{f}$ Annemieke Dhondt ${ }^{f}$ Dries Deeren ${ }^{g}$ Jan Ptak ${ }^{h}$ Milan Blaha ${ }^{i}$ Mirka Lanska ${ }^{i}$ \\ Zdenka Gasovaj Zdenka Bhuiyan-Ludvikovaj Radomira Hrdlickovak ${ }^{j}$ Wolfgang Ramlow ${ }^{\prime}$ \\ Heinrich Prophet ${ }^{1} \quad$ Jan T. Kielstein ${ }^{m} \quad$ Giancarlo Liumbruno $^{n} \quad$ Elena Morio $^{\circ}$ Antanas Griskevicius $^{p}$ \\ Judita Audzijoniene $^{p}$ Hans Vrielink ${ }^{q}$ Eva Rombout-Sestrienkova ${ }^{q}$ Astrid Aandahl ${ }^{r}$ \\ Aleksandar Sikole $^{\mathrm{s}}$ Jorge Tomaz ${ }^{\mathrm{t}}$ Katarina Lalic ${ }^{\mathrm{u}}$ Ines Bojanic ${ }^{\mathrm{V}}$ Virginia Strineholm ${ }^{\mathrm{w}}$ \\ Bo Brink $^{x}$ Gösta Berlin ${ }^{y}$ Josefina Dykes ${ }^{z}$ Thomas Nilsson ${ }^{A}$ Torsten Eich ${ }^{B}$ Henrik Hadimeri $^{C}$ \\ Gunilla Welander $^{\mathrm{D}}$ Sandra Ortega Sanchez ${ }^{\mathrm{E}}$ Osman Ilhan ${ }^{\mathrm{F}}$ Colwyn Poole $^{\mathrm{G}}$ \\ a Public Health and Clinical Medicine, Umeå University, Umeå, Sweden; ${ }^{b}$ Bone Marrow Transplant and Apheresis, \\ Concord, NSW, Australia; ' St. Anna, Pediatric Department, Vienna, Austria; ${ }^{d}$ Apheresis Unit, Renal, AKH, Vienna, Austria; \\ ${ }^{\mathrm{e}}$ Apheresis Unit, Haematological, AKH, Vienna, Austria; ${ }^{\mathrm{f} D e p a r t m e n t ~ o f ~ N e p h r o l o g y, ~ U n i v e r s i t y ~ H o s p i t a l, ~ G h e n t, ~ B e l g i u m ; ~}$ \\ gDepartment of Hematology, AZ Delta, Roeselare, Belgium; ${ }^{\mathrm{h}}$ Transfusion Medicine, Frydek-Mistek, Czech Republic; \\ 'Hemapheretic Center of the 3rd Department of Medicine, Medical Faculty and University Hospital, Hradec Kralove, \\ Czech Republic; ${ }^{j}$ Institute of Hematology and Blood Transfusion, Prague, Czech Republic; ${ }^{k}$ Apheresis Unit, University \\ Hospital, Ostrava, Czech Republic; 'Apheresis Center North, Rostock, Germany; ${ }^{\mathrm{m}}$ Nephrology, Rheumatology, Blood \\ Purification, Academic Teaching Hospital, Braunschweig, Germany; ${ }^{n}$ Italian National Blood Centre, National Institute \\ of Health, Rome, Italy; ${ }^{\circ}$ Blood Center, Livorno, Italy; ${ }^{\mathrm{P} T h e r a p e u t i c ~ A p h e r e s i s ~ U n i t, ~ U n i v e r s i t y ~ H o s p i t a l, ~ V i l n i u s, ~ L i t h u a n i a ; ~}$

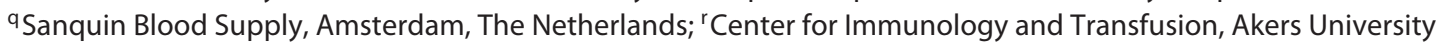 \\ Hospital, Loerenskog, Norway; ${ }^{\mathrm{s}}$ Department of Nephrology, University Hospital, Skopje, North Macedonia; ${ }^{\mathrm{t} A p h e r e s i s}$ \\ Unit, Coimbra University Hospital, Coimbra, Portugal; "Institute for Endocrinology, University Hospital, Belgrade, Serbia;

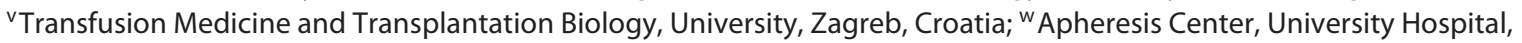 \\ Orebro, Sweden; ${ }^{x}$ Department of Nephrology, University Hospital, Huddinge, Sweden; ${ }^{y}$ Clinical Immunology and \\ Transfusion Medicine, Linköping University, Linköping, Sweden; ${ }^{2}$ Apheresis Center, University Hospital, Lund, Sweden; \\ A Department of Nephrology, University Hospital, Uppsala, Sweden; ${ }^{B}$ Blood Center, University, Uppsala, Sweden, \\ Uppsala, Sweden; ${ }^{C}$ Department of Nephrology, Skaraborg Hospital, Skövde, Sweden; DDepartment of Nephrology,

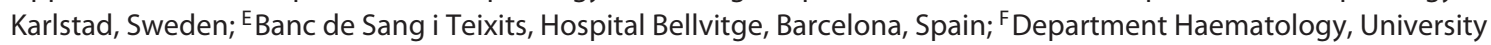 \\ Hospital, Ankara, Turkey; ${ }^{G}$ South African National Blood Service, Johannesburg, South Africa
}

\section{Keywords}

Registry · Apheresis · Adverse events · Diagnoses

\section{Abstract \\ Therapeutic apheresis (TA) is prescribed to patients that suf- fer from a severe progressive disease that is not sufficiently treated by conventional medications. A way to gain more}

knowledge about this treatment is usually by the local analysis of data. However, the use of large quality assessment registries enables analyses of even rare findings. Here, we report some of the recent data from the World Apheresis Association (WAA) registry. Data from $>104,000$ procedures were documented, and TA was performed on $>15,000$ patients. The main indication for TA was the collection of autologous stem cells ( $45 \%$ of patients) as part of therapy for 
therapy. Collection of stem cells from donors for allogeneic transplantation was performed in $11 \%$ of patients. Patients with indications such as neurological diseases underwent plasma exchange (28\%). Extracorporeal photochemotherapy, lipid apheresis, and antibody removal were other indications. Side effects recorded in the registry have decreased significantly over the years, with approximately only $10 / 10,000$ procedures being interrupted for medical reasons. Conclusion: Collection of data from TA procedures within a multinational and multicenter concept facilitates the improvement of treatment by enabling the analysis of and feedback on indications, procedures, effects, and side effects.

(c) 2021 S. Karger AG, Basel

\section{Introduction}

Therapeutic apheresis (TA) is performed for numerous indications in various fields of medicine with a changing panorama of indications [1-6]. The proportions and techniques used for apheresis in different diseases also vary between countries and centers [5]. Although there are guidelines that help the clinician to motivate the inclusion of patients into the TA program, reimbursement for apheresis from insurance or hospital budgets differs between countries, which results in differences in inclusion criteria.

The results of registry data on indications, side effects, and effects of therapy for patients undergoing TA on the local, national, and international levels can guide physicians and politicians in their decisions about whether to accept or avoid therapy; these decisions must be based on the local resources, costs, and risks versus benefits for patients. At a meeting held in Paris in 2002, the World Apheresis Association (WAA) registry was developed from the concepts of the Canadian, French, and Swedish national registries already in existence [7-10]. The progressive participation of centers and countries has improved the extent of available data and thereby increased statistical power. Registry reports have included data that help understand effects and side effects in the process of collecting blood and plasma for autologous or allogeneic measures $[4,5,11-17]$. This paper deals with the distribution of some diagnoses and reports recent data of side effects included in the WAA registry.

\section{Material and Methods}

Centers that have submitted data to the WAA registry applied and received access via the homepage: www.waa-registry.org. The WAA registry requests that centers include all TA procedures, even routine ones, and it is not specifically designed to assess TA procedures with side effects only. The purpose is to achieve a con-
Table 1. Grading of side effects

\begin{tabular}{ll}
\hline Code & Explanation/help \\
\hline 1 & Mild adverse event (AE)/no medication needed \\
\hline 2 & Moderate adverse event (AE)/medication needed \\
\hline 3 & $\begin{array}{l}\text { Severe adverse event (AE)/medication needed and } \\
\text { apheresis interrupted }\end{array}$ \\
\hline 4 & Died due to apheresis \\
\hline
\end{tabular}

secutive collection of data that enables an improved analysis. Data on patients who did not give their consent are excluded.

Data collection included variables such as gender, age, diagnosis, treatment mode, anticoagulation, and substitution fluids, reasons for treatment interruption, and the grade and type of side effect when these occur. In addition, numerous diagnoses may be graded according to their outcome over the treatment period. Grading of side effects is shown in Table 1: "Mild" (no need of medication due to side effects), "Moderate" (medication needed due to side effects), "Severe" (interruption of therapy due to side effects), and "Death" (due to the side effects of apheresis). Specific grading systems are used for different diseases.

The treatment is performed based on the quality of therapy assessment principles. The new European integrity regulations stipulate obtaining informed consent from the patient when they are in a state to respond, and consent from parents for children to undergo therapy. Within the WAA registry, the identity of the patient is converted into a local coding system which keeps the identity of the patient confidential. Participation by a center will enable it to download its own data for local reports and for comparison with the whole data pool, to be able to check if the local quality is above, below, or within the range at all other centers.

\section{Results and Discussion}

An increasing number of centers are participating in the WAA registry. Data are entered consecutively, and no selection is made of specific procedures with or without deviations. A total of 104,000 procedures were performed in 15,651 patients. Women represented $42 \%$ of all patients and $42.5 \%$ of treatments. The median age of patients at the start of therapy was 55 years. During the last 5 years, a total of 7,770 patients underwent 49,450 procedures. The type of apheresis procedures performed within the frame of the registry from 2014 up to and including 2018 are displayed in Table 2 . The most common devices used in the procedures are displayed in Table 3.

The proportions of different degrees of side effects are illustrated in Figure 1. The occurrence of side effects (including severe ones) has decreased significantly over time, from $11 \%$ of apheresis procedures in 2003 to approximately $2.3 \%$ in 2018 ( $p<0.001)$. Of these, $0.6 \%$ procedures resulted in mild side effects, $1.6 \%$ in moderate side effects, and $0.1 \%$ in severe side effects that caused interruption of the apheresis. One death that may have 
Table 2. Proportion of patients undergoing the most frequent specific apheresis procedures (2014-2018)

\begin{tabular}{lc}
\hline & $\%$ \\
\hline Procedure & \\
Plasma exchange (centrifugation) & 28.0 \\
Extracorporeal photochemotherapy (ECPT) & 3.6 \\
Erythrapheresis & 2.7 \\
Cascade filtration & 1.7 \\
Leukapheresis by filtration/adsorption & 1.7 \\
Exchange of erythrocytes & 1.0 \\
Depletion of erythrocytes & 0.8 \\
Plasma exchange (filtration) & 0.8 \\
Absorption: ABO-mismatch & 0.7 \\
Platelet apheresis & 0.6 \\
IgG adsorption globaffin column & 0.2 \\
Filtration, free light chain removal & 0.2 \\
LDL-removal & 0.2 \\
Protein A adsorber & 0.2 \\
IgE adsorption & 0.1 \\
Rheopheresis & 0.1 \\
IgG adsorption, sheep antibody & 0.1 \\
Plasma and lymphapheresis & $<0.1$
\end{tabular}

Preparative procedure

Peripheral blood stem cell collection Autologous Allogeneic
Table 4. Severe side effects causing interruption of the apheresis procedure (a total of 41 symptomatic episodes appeared out of 49,400 procedures representing 8 severe events/10,000 procedures)

\begin{tabular}{lc}
\hline Finding & $n(\%)$ \\
\hline Hypotension & $11(26.8)$ \\
Urticaria, conjunctivitis & $8(19.5)$ \\
Abdominal pain & $6(14.6)$ \\
Cardiac arrest (resuscitated) & $2(4.9)$ \\
Bronchospasm & $2(4.9)$ \\
Nausea and/or vomiting & $2(4.9)$ \\
Tingling, stitching & $2(4.9)$ \\
Chills and fever $\left(>38^{\circ} \mathrm{C}\right)$ & $2(4.9)$ \\
Anaphylactic shock & $1(2.4)$ \\
Arrhythmia & $1(2.4)$ \\
Hypertension & $1(2.4)$ \\
Back pain related to apheresis & $1(2.4)$ \\
Flush & $1(2.4)$ \\
Late complication, other & $1(2.4)$ \\
\hline
\end{tabular}

been related to apheresis was reported in the total of 104,000 treatments. This case was an elderly, severely ill patient who died from myocardial infarction during the procedure. During the 49,400 procedures performed in 2014-2018, 46 severe side effects related to the apheresis itself caused interruption of the procedure. Of these, 5
Table 3. The most frequently used devices for performing apheresis in 2014-2018

Company, device

TerumoBCT, Optia

Haemonetics, MCS -kit

Theracos, cellex

Fresenius, comtec

Terumo BCT, Cobe Spectra

Fresenius, Dali

Fresenius, MONET

Kaneka, DX-21

DiaMed, Octa Nova

Other systems

Kaneka, MA-03 (whole blood)

Kaneka, DL 100

Asahi KASEI, Immusorba TR 350

Fresenius Kabi, Amicus

Otsuka, Adacolumn

Medicap, ADAsorb Immunadsorption

Asahi KASEI, Immusorba PH 350

BBraun, Plasmat Futura

Fresenius, Multifiltrate device

Terumo BCT, TRIMA

Miltenyi Biotec, LIFE 18 \& 21

Therakos, Uvar

Gambro, Prismaflex

Kaneka, MA-03 (La-15DL)

Fresenius, Art -Universal

Nikisso, Immunopure LPM-01

were due to access problems. The severe side effects of TA during the last 5 years are given in Table 4 . The WAA registry allows interaction regarding information recorded in the registry on an immediate basis. This enables users to get fast responses to questions that may arise.

The most common procedure is apheresis for stem cell collection. Stem cells are mainly used by cancer patients with cells being reinfused after oncologic therapy. The cells collected are for autologous or allogeneic transplantation.

Differentiation of analyses of apheresis is made possible by separating the indications according to diagnosis (ICD-10 code). This enables specific analysis of the treatment of a disease, e.g., sickle cell disease. The side effects differ depending on the mode of therapy but also on the replacement fluid used; for instance, hypotension was found to be more common if albumin only (and not plasma) was used as replacement, while urticaria was mainly related to replacement with plasma [4]. As shown by Norda et al. [18], hypotension was more frequent if the albumin concentration was $3.5 \%$ instead of $5 \%$ (risk ratio 4.0 ; $95 \%$ confidence interval [CI] 1.5-10.2; $p<0.001$ ). This knowledge can help to guide patients and clinicians to prepare for the therapy. 
Table 5. Distribution of diagnoses (given as ICD-10 codes) as a percentage of a total of 644 patients treated for neurological diseases in 2014-2018 ( $\geq 0.3 \%$ of neurological therapeutic indications are displayed; 31 other diagnoses are less represented in the WAA registry)

\begin{tabular}{lll}
\hline$\%$ & ICD-10 & Diagnosis \\
\hline 29.0 & G700 & Myasthenia gravis \\
19 & G35 & Multiple sclerosis \\
18.8 & G610 & Guillain-Barré syndrome \\
5.7 & G619B & Inflammatory polyneuropathy, unspecified \\
4.0 & G99A & Autonomic neuropathy related to endocrine and metabolic diseases \\
2.6 & G049 & Encephalitis, myelitis, and encephalomyelitis, unspecified \\
2.3 & G360 & Neuromyelitis optica \\
2.2 & G629 & Polyneuropathy, unspecified \\
1.4 & G618 & Other specified polyneuropathies \\
1.1 & G0481 & Encephalomyelitis \\
0.8 & G040 & Acute disseminated encephalomyelitis \\
0.8 & G6181 & CIDP (chronic inflammatory demyelinating polyneuropathy) \\
0.8 & G98 & Other diseases of the nervous system not specified in another location \\
0.6 & G0481 & Limbic encephalitis \\
0.5 & I677 & Susac syndrome \\
0.5 & G049A & Encephalitis, unspecified \\
0.5 & G2582 & Stiff-man syndrome \\
0.5 & G600 & Sensory polyneuropathy \\
0.5 & G731 & Lambert-Eaton syndrome \\
0.5 & G934 & Encephalopathy, unspecified \\
0.3 & G318 & ANEC (acute necrotizing encephalopathy of childhood) \\
0.3 & G049B & Myelitis, unspecified \\
0.3 & G373 & Acute transversal myelitis \\
0.3 & G379 & Demyelinating disease, unspecified \\
0.3 & G409 & Epilepsy \\
0.3 & G611 & Serum neuropathy \\
0.3 & G6181 & Optic neuritis \\
0.3 & G728 & Myopathies and rhabdomyolysis \\
0.3 & G804 & Ataxic cerebral palsy \\
0.3 & G99A & Paraneoplastic syndromes \\
\hline
\end{tabular}

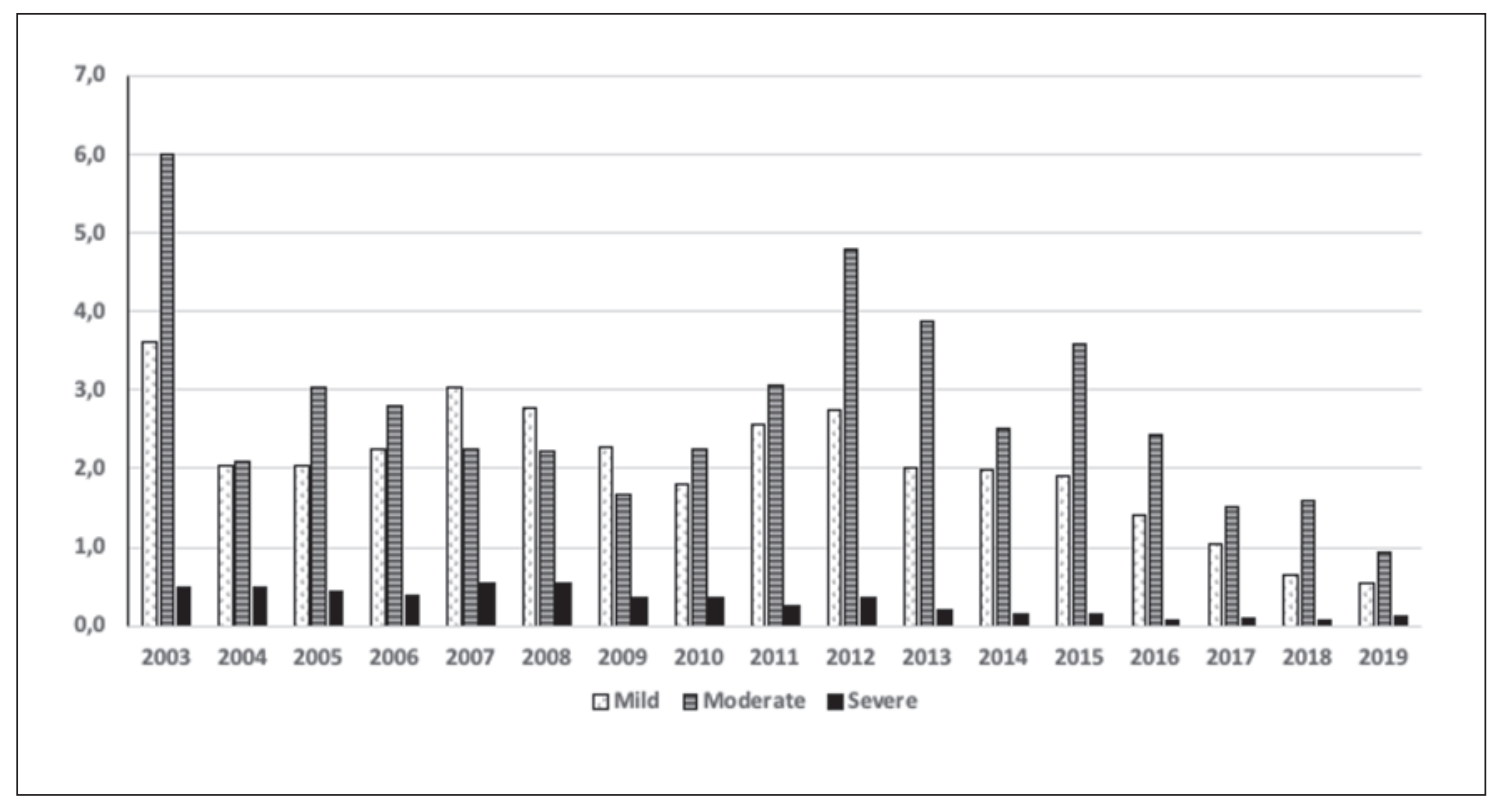

Fig. 1. Distribution of the different grades of adverse events considered to be due to the apheresis procedure (from 2003 to June 2019). 
During recent years, indications for TA for neurological diseases have increased. Table 5 displays some common neurological indications for apheresis in $644 \mathrm{pa}-$ tients who suffered from 66 different diagnoses. The large number of patients with new neurological diagnoses that are offered TA is in parallel with the increased knowledge of antibody-mediated diseases aside from inflammation and infection [19-27]. This stresses the need for developing new methods to detect previously unknown antibodies.

A limitation of the WAA registry is that only a few centers enter outcome data, although the registry allows such entries. One reason may be that the clinician responsible does not actually write up the TA report submitted to the registry. In addition, the physician at the apheresis unit may be unaware of the various stages, i.e., improvement or impairment, that might have developed at the specific ward. The local staff at the apheresis unit may communicate with the patient and enter data on a rough scale that estimates the patient's functional capacity (e.g., from being unconscious to performing athletic competition exercise) by asking the patient questions. These data can also be relevant and are currently being analyzed.

So far, only aggregated data have been reported. Retrospective follow-up of outcome data has been performed for thrombotic microangiopathy, and this is underway for some other conditions. No interventional studies have been included thus far, but it is possible to enter these into the frame of the electronic system.

One benefit offered by this multicenter registry is that the participating centers can compare their data with other centers (aggregate data). The system does not involve extra costs for the users. Approximately 40 variables can be analyzed. Each center may analyze their own data whenever necessary. Longitudinal analyses can be performed of outcomes of multiple variables over time. Separate diagnoses have been given various outcome criteria.

A risk of selection bias exists, mainly due to some patients not consenting to their data being used for quality assessment and improvement. It is rare that units omit entering data about a procedure. The collection of outcome data is limited, however, mainly due to poor feedback from the clinician to the person who submits the data to the registry.

Most patients treated by extracorporeal photopheresis suffer from graft versus host disease [5]. Stem cell collection is mainly performed by autologous means for cancer treatment [5]. Notably, approximately $10 \%$ of cell collection procedures are performed on donors.

The decrease in side effects over time is most likely due to the increased awareness of the causes of problems that can arise, e.g., a low concentration of albumin in the return fluid will increase the risk for hypotension. Aware- ness obtained from data analyses and access to other publications increase the knowledge of how to prevent side effects at all participating centers. Analysis of data from the Swedish registry showed that side effects during TA differed for various diseases [18, 28-32]. Replacement and processing techniques are other markers to refer to [33]. The standardization of stem cell collection may be responsible for the small number of adverse events in this population compared to in patients performing direct therapeutic plasma exchange [4]. Differences between centers also are present, and this encourages specific statistical analyses and interpretations [34].

In conclusion, this report on the WAA registry shows that the combined use and interactive communications between participating centers enable the analysis of large amounts of data. The feedback within centers may be one reason for the significant reduction of especially severe side effects. Although many patients suffer from lifethreatening diseases, when treatment is performed, the addition of this extracorporeal therapeutic approach seems fairly well tolerated. We invite more centers to apply for participation in the registry to enter data to enable further knowledge of therapeutic measures and side effects. The application can be made at www.waa-registry. org.

\section{Acknowledgement}

Our thanks for funding go to the Swedish National Registry authority that enabled establishment of the Web-based internationally available registry. Njurföreningen Västerbotten and Sweden's municipalities and regions also gave their support. The World Apheresis Association supported coordinating meetings.

\section{Conflict of Interest Statement}

None of the authors have a conflict of interest.

\section{Funding Sources}

We received funds from the Swedish National Registry, Njurföreningen Västerbotten, and Sweden's municipalities and regions. 


\section{References}

1 Schwartz J, Padmanabhan A, Aqui N, Balogun RA, Connelly-Smith L, Delaney M, et al. Guidelines on the Use of Therapeutic Apheresis in Clinical Practice-Evidence-Based Approach from the Writing Committee of the American Society for Apheresis: The Seventh Special Issue. J Clin Apher. 2016 Jun;31(3): 149-62.

2 De Silvestro G. The Italian registry of therapeutic apheresis - 2015. Transfus Apheresis Sci. 2017 Feb;56(1):75-81.

3 De Silvestro G, Tison T; Italian Society of Apheresis and Cell Manipulation (SIdEM). Italian Registry of Therapeutic Apheresis. Transfus Apher Sci. 2018 Apr;57(2):143-47.

4 Mörtzell Henriksson M, Newman E, Witt V, Derfler K, Leitner G, Eloot S, et al. Adverse events in apheresis: an update of the WAA registry data. Transfus Apher Sci. 2016 Feb; 54(1):2-15.

5 Stegmayr B, Mortzell Henriksson M, Newman E, Witt V, Derfler K, Leitner G, et al. Distribution of indications and procedures within the framework of centers participating in the WAA apheresis registry. Transfus Apher Sci. 2017 Feb;56(1):71-4.

6 Padmanabhan A, Connelly-Smith L, Aqui N, Balogun RA, Klingel R, Meyer E, et al. Guidelines on the Use of Therapeutic Apheresis in Clinical Practice - Evidence-Based Approach from the Writing Committee of the American Society for Apheresis: The Eighth Special Issue. J Clin Apher. 2019 Jun;34(3):171-354.

7 Stegmayr BG, Ivanovich P, Korach JM, Rock G, Norda R, Ramlow W. World apheresis registry. J Clin Apher. 2005 Jul;20(2):126-7.

8 Stegmayr BG, Ivanovich P, Korach JM, Rock G, Norda R, Ramlow W. World apheresis association-world apheresis registry. Transfus Apher Sci. 2005 Apr;32(2):205-7.

9 Stegmayr B, Korach JM, Norda R, Rock G, Fadel F. Is there a need for a national or a global apheresis registry? Transfus Apher Sci. 2003 Oct;29(2):179-85.

10 Stegmayr B. The World Apheresis Association Registry. Transfus Apher Sci. 2007 Feb; 36(1):13-6.

11 Stegmayr B, Ptak J, Wikstrom B. World apheresis registry report. Transfus Apher Sci. 2007 Feb;36(1):13-6.

12 Stegmayr B, Ptak J, Wikström B, Berlin G Axelsson CG, Griskevicius A, et al. World apheresis registry 2003-2007 data. Transfus Apheresis Sci. 2008 Dec;39(3):247-54.
13 Witt V, Stegmayr B, Ptak J, Wikström B, Berlin G, Axelsson CG, et al. World apheresis registry data from 2003 to 2007, the pediatric and adolescent side of the registry. Transfus Apheresis Sci. 2008 Dec;39(3):255-60.

14 Blaha M, Ptak J, Blazek M, Lanska M, Prochazkova R, Ceeova V, et al. Waa Apheresis Register - Results in Czech Republic. Haematol-Hematol J. 2009;94:683.

15 Blaha M, Ptak J, Cap J, Ceeova V, Masin V, Filip S, et al. WAA apheresis registry in the Czech Republic: two centers experience. Transfus Apher Sci. 2009;41(1):27-31.

16 Mortzell M, Berlin G, Nilsson T, Axelsson CG, Efvergren M, Audzijoni J, et al. Analyses of data of patients with Thrombotic Microangiopathy in the WAA registry. Transfus Apher Sci. 2011;45(2):125-31.

17 Stegmayr B, Ptak J, Nilsson T, Berlin G, Mirea $\mathrm{V}$, Axelsson CG, et al. Panorama of adverse events during cytapheresis. Transfus Apher Sci. 2013;48(2):155-6.

18 Norda R, Axelsson CG, Axdorph U, Berlin G, Wikström B, Stegmayr B; Swedish Apheresis Group. Recognition of intercenter differences may help develop best practice. Ther Apher Dial. 2008 Oct;12(5):347-54.

19 Bing-Lei W, Jia-Hua Z, Yan L, Zan Y, Xin B, Jian-Hua $S$, et al. Three cases of antibodyLGI1 limbic encephalitis and review of literature. Int J Neurosci. 2019 Jul;129(7):642-8.

20 Esposito S, Principi N, Calabresi P, Rigante D. An evolving redefinition of autoimmune encephalitis. Autoimmun Rev. 2019 Feb;18(2): 155-63.

21 Jones RB, Hiemstra TF, Ballarin J, Blockmans DE, Brogan P, Bruchfeld A, et al.; European Vasculitis Study Group (EUVAS). Mycophenolate mofetil versus cyclophosphamide for remission induction in ANCA-associated vasculitis: a randomised, non-inferiority trial. Ann Rheum Dis. 2019 Mar;78(3):399-405.

22 McAdoo SP, Medjeral-Thomas N, Gopaluni S, Tanna A, Mansfield N, Galliford J, et al. Long-term follow-up of a combined rituximab and cyclophosphamide regimen in renal anti-neutrophil cytoplasm antibody-associated vasculitis. Nephrol Dial Transplant. 2019 Jan;34(1):63-73

23 Patterson K, Iglesias E, Nasrallah $M$, González-Álvarez V, Suñol M, Anton J, et al. Anti-MOG encephalitis mimicking small vessel CNS vasculitis. Neurol Neuroimmunol Neuroinflamm. 2019 Feb;6(2):e538.
24 Pepper RJ, McAdoo SP, Moran SM, Kelly D, Scott J, Hamour S, et al. A novel glucocorticoid-free maintenance regimen for anti-neutrophil cytoplasm antibody-associated vasculitis. Rheumatology (Oxford). 2019 Feb;58(2): 260-8.

25 Si Z, Wang A, Liu J, Zhang Z, Hu K. Typical clinical and imaging manifestations of encephalitis with anti- $\gamma$-aminobutyric acid B receptor antibodies: clinical experience and a literature review. Neurol Sci. 2019 Apr;40(4): 769-77.

26 Strunk D, Schmidt-Pogoda A, Beuker C, Milles LS, Korsukewitz C, Meuth SG, et al. Biomarkers in Vasculitides of the Nervous System. Front Neurol. 2019 Jun; 10:591.

27 Stuhlmüller B, Schneider U, GonzálezGonzález JB, Feist E. Disease Specific Autoantibodies in Idiopathic Inflammatory Myopathies. Front Neurol. 2019 May;10:438.

28 Norda R, Berséus O, Stegmayr B. Adverse events and problems in therapeutic hemapheresis. A report from the Swedish registry. Transfus Apheresis Sci. 2001 Aug;25(1):3341.

29 Norda R, Knutson F, Berseus O, Akerblom O, Nilsson-Ekdahl K, Stegmayr B, et al. Unexpected effects of donor gender on the storage of liquid plasma. Vox Sang. 2007 Oct;93(3): 223-8.

30 Norda R, Schött U, Berséus O, Akerblom O, Nilsson B, Ekdahl KN, et al. Complement activation products in liquid stored plasma and C3a kinetics after transfusion of autologous plasma. Vox Sang. 2012 Feb;102(2):125-33.

31 Norda R, Stegmayr BG; Swedish Apheresis Group. Therapeutic apheresis in Sweden: update of epidemiology and adverse events. Transfus Apheresis Sci. 2003 Oct;29(2):15966.

32 Norda R, Stegmayr BG; Swedish Apheresis Study Group. Apheresis registry in Sweden: scope, techniques and indications for treatment. A report from the Swedish apheresis study group. Transfus Apheresis Sci. 2001 Feb;24(1):49-55.

33 Stegmayr B, Tärnvik A. Complement activation in plasma exchange by single filtration and centrifugation and in cascade filtration. Blood Purif. 1989;7(1):10-5.

34 Toss F, Edgren G, Berlin G, Stegmayr B, Witt V. Does prophylactic calcium in apheresis cause more harm than good? - Centre heterogeneity within the World Apheresis Association Register prevents firm conclusions. Vox Sang. 2018 Oct;113(7):632-8. 